\title{
Responses of regeneration and species coexistence to single-tree selective logging for a temperate mixed forest in eastern Eurasia
}

\author{
Lin $\mathrm{Qi}^{1} \cdot$ Jian Yang $^{2} \cdot$ Dapao $\mathrm{Yu}^{1} \cdot$ Limin $\mathrm{Dai}^{1} \cdot$ Marco Contrereas $^{2}$
}

Received: 15 July 2015 / Accepted: 6 January 2016/Published online: 28 January 2016

(C) INRA and Springer-Verlag France 2016

\begin{abstract}
- Key messages The altered proportion of Korean pine to broadleaved tree species following selective logging strongly affected post-harvest regeneration and species coexistence pattern in a temperate mixed broadleaved/ Korean pine forest in eastern Eurasian. Species interaction should be considered when implementing selective logging schemes.
\end{abstract}

\footnotetext{
Handling Editor: Aaron R Weiskittel

Contribution of the co-authors Lin Qi: Designing the experiment, writing the paper, and running the data analysis.

Jian Yang: Supervising the work and writing the paper.

Dapao Yu: Designing the experiment.

Limin Dai: Coordinating the research project

Marco Contrereas: writing the paper
}

Jian Yang

jian.yang@uky.edu

Lin Qi

qilin@iae.ac.cn

Dapao Yu

yudp2003@iae.ac.cn

Limin Dai

lmdai@iae.ac.cn

Marco Contrereas

marco.contreras@uky.edu

1 State Key Laboratory of Forest and Soil Ecology, Institute of Applied Ecology, Chinese Academy of Sciences, Shenyang 110164, People's Republic of China

2 Department of Forestry, University of Kentucky, TP Cooper Building, Lexington, KY 40546, USA
- Context It has been documented widely that selective logging can exert varied influences on post-harvested forest structure and dynamics via different logging intensity and rotation. However, few studies have been extended to evaluate the effects of the tree species selected for removal, which is also a critical component in prescribing a selective harvest plan.

- Aims To clarify the effects and underlying mechanisms of logged tree species selection on species coexistence and regeneration pattern in post-harvested mixed broadleaved/ Korean pine (Pinus koraiensis Siebold \& Zucc.) forest in Changbai Mountains, China.

- Methods Four types of plots were established based on different selection of logged tree species. Stand structure, spatial distribution pattern and spatial association of major tree species were analyzed using spatial point pattern (SPP) analysis. The effect of soil nitrogen concentration on forest regeneration was also examined through a Pearson correlation analysis.

- Results Sapling density of both Korean pine and commercially valuable broadleaved tree species was significantly greater on plots where Korean pines were logged than on plots where only commercial broadleaved trees were removed. Soil $\mathrm{N}$ and density of saplings were not correlated. SPP analysis showed strong negative spatial association between mature Korean pine and saplings of most tree species in most sampling plots.

- Conclusion The proportion of Korean pine to broadleaved tree species selected for removal can lead to different stand structure and spatial distribution patterns of tree locations. Due to species-specific competition effects, such variations in spatial association of tree locations can exert varied effects on regeneration in this pine-dominated Eurasian temperate forest. To promote post-harvest tree regeneration and species coexistence, forest managers in this region should consider 
controlling the density of competition-superior trees such as large-size Korean pines when implementing a selective logging scheme.

Keywords Selective logging · Competition · Spatial association $\cdot$ Spatial point pattern $\cdot$ Mixed broadleaved/Korean pine forest $\cdot$ Regeneration

\section{Introduction}

The selective logging system is one of the methods most widely employed for commercial timber production in natural forests (Noble and Dirzo 1997). It is based theoretically on the natural forest process of self-thinning or natural disturbance regime (Bischoff et al. 2005; Castro-Luna et al. 2011; Wu et al. 2013). Selective logging (cutting a single tree or small group in a stand) creates a gap that can improve understory light conditions, promote the growth of seedlings and young trees, alter the resulting forest composition, and form more habitats for species coexistence and conservation of biodiversity (Bréda et al. 1995; Verschuyl et al. 2011). Changes in those factors are crucial in determining forest regeneration developments, and subsequently exert profound influences on post-logging forest structure and dynamics (Fajardo et al. 2006). Selective logging schemes can be implemented based on logging intensity, rotation, and selection of tree species for removal. Many studies have investigated the impact of logging intensity and rotation on forest dynamics and sustainability (Sist et al. 2003; Nagaike and Hayashi 2004; Soalleiro et al. 2007; Moore et al. 2012; Pope et al. 2015), but few have extended their studies to evaluate the effects of tree species selected for removal - even though it is also a critical component in prescribing a selective harvest plan.

In various natural temperate forests, regeneration patterns are driven mainly by the balance of resource availability and interactions among inter-specific and intra-specific tree individuals (Fernandez et al. 2008; Linares 2013). At the stand scale, these factors are determined primarily by large trees, and are spatially heterogeneous and species specific. Selective logging based on tree size and species can affect regeneration patterns through its influence on the type and quantity of the resources released (e.g., water and nutrients) previously occupied by specific individuals, as well as by altering species interactions (e.g., competition and facilitation) due to variable post-logging species composition and tree locations. Selection of different tree species for removal may lead to a shift in the relative importance of these two broad driving mechanisms (Canham et al. 2006) and, ultimately, determine forest regeneration and species coexistence patterns.

Understanding species coexistence is increasingly recognized as being of both theoretical and practical importance in managing forests (Ishii et al. 2004; Odion and Sarr 2007). Considerable progress has been made using spatial point pattern (SPP) analysis to understand biodiversity and related ecological mechanisms in forests (Martinez et al. 2010; Wang et al. 2011). The spatial distribution patterns (e.g., aggregation, random, or regularity) and associations (positive or negative) of individual trees can reflect the interaction among individual trees and the influence of their habitats. Empirical studies have shown that spatial and size distributions of trees in a community bear the fingerprint of two important mechanisms: competition and resource partitioning. Competition often results in a regular, non-random distribution of trees at fine scales because individuals exclude their neighbors by competing for the same resources (Getzin et al. 2006; Wang et al. 2011). Resource partitioning, or habitat filtering, is a major influence in the formation of aggregated distributions because individuals grow fastest where their soil and other resource requirements are best met (Palmiotto et al. 2004; Getzin et al. 2008). Researchers now generally agree that these two mechanisms are not mutually exclusive, made evident by the existence of spatial association influenced by both competition and resource partitioning but with varied relative importance under different scales (Harms et al. 2001; Wang et al. 2011). However, most previous studies were conducted in undisturbed forests. In addition, the effects and underlying mechanisms of logged tree species selection on species coexistence and regeneration pattern in post-harvested forests were rarely the focus in those studies. Sites that originate from the same forest, but in which different selective logging systems have been applied, provide an unintentional 'management experiment'. The response of spatial distribution and spatial correlation of trees in a stand to selective logging can not only be capitalized to gain insights about the mechanisms of tree species coexistence, but also may offer a more reliable basis for predicting forest dynamics and sustainability under different management practices.

In this study, we applied SPP analysis to elucidate species coexistence mechanisms in a selectively logged forest that is distributed widely in the temperate zone of Northeast China. The dominant forest type in this region is mixed broadleaved/ Korean pine forest. Korean pine (Pinus koraiensis Siebold \& Zucc.) is a late-successional competitively superior keystone species that accounts for about $40 \%$ stand volume of these forests (Yu et al. 2011). Not only do these temperate forests provide timber, but they also are well known for their high species richness and distinctive composition. Economically, the forest in this region supplies more timber and wood products than most other forested regions in China. Ecologically, many species are endemic to this region and very sensitive to climate changes and human disturbance (Zhao et al. 2011). Forest harvesting in this region began in the 1950s when state-owned forestry bureaus were established (Dai et al. 2011b). Excessive timber harvesting was encouraged and 
clear-cutting was the primary method until the 1980s when forestry bureaus began to adopt selective logging to balance timber production and resource protection. But Korean pine continued to be over-utilized, thus resulting in a reduction in timber resources (Yu et al. 2011). To counter this trend, national and local governments have, since 2000, instituted a plan with multiple management objectives for sustainable forest development called the Natural Forest Conservation Program (NFCP) (Dai et al. 2009). The aim of the NFCP is to balance timber production and the ecological benefits of forest ecosystems such as soil erosion reduction, water resource conservation, and biodiversity maintenance (Shao et al. 2005; Dai et al. 2013). After the NFCP was initiated, harvesting of Korean pine was prohibited (Zhao et al. 2011). This prohibition nevertheless failed to restore Korean pine to its previous level of dominance, owing to its poor natural regeneration in those selectively logged forests (Yu et al. 2011). While several studies have reported the effects of logging intensity on forest stand structure and composition (Dai et al. 2011a, 2004), few studies have evaluated how different tree species selected for logging might change spatial relationships among the remaining uncut trees and newly regenerated saplings and thereby influence forest structure and dynamics.

In this study, we spatially located all live trees $>2 \mathrm{~cm}$ diameter at breast height (DBH) with their species ID and DBH recorded and measured total soil nitrogen (TN) in two control (unlogged) sites and nine logged sites where three methods of selecting tree species for removal were applied (see data collection below). Then, we used SPP analysis to determine the fine-scale distributional patterns of both remaining and post-logging regenerated trees among logging treatments. We hypothesized that (1) the type and quantity of resource released via logging Korean pine may differ from logging broadleaved tree species, which may lead to different stand structure and spatial distribution patterns of tree locations; (2) because interaction types (e.g., competition and facilitation) may vary by tree species, the proportion of Korean pine to broadleaved tree species selected for removal can lead to variations in spatial associations of individual trees within a forest stand; and (3) soil nitrogen also plays an important role in determining regeneration tree density and their spatial distribution patterns, as the quantity and quality of major nutrients are also an important limitation factor of tree growth and regeneration.

\section{Materials and methods}

\subsection{Study site and experimental design}

The study was conducted on the northwestern slopes of Changbai Mountain, northeastern China (latitude $42^{\circ} 24^{\prime}-$ $42^{\circ} 49^{\prime} \mathrm{N}$, longitude $127^{\circ} 29^{\prime}-128^{\circ} 02^{\prime} \mathrm{E}$ ). All stands were located in Lushuihe Forestry Bureau (Fig. 1, Table 1), which ranges in elevation from 600 to $1,000 \mathrm{~m}$. The climate of this area is characterized by long, cold, windy winters and short, wet summers. Average annual

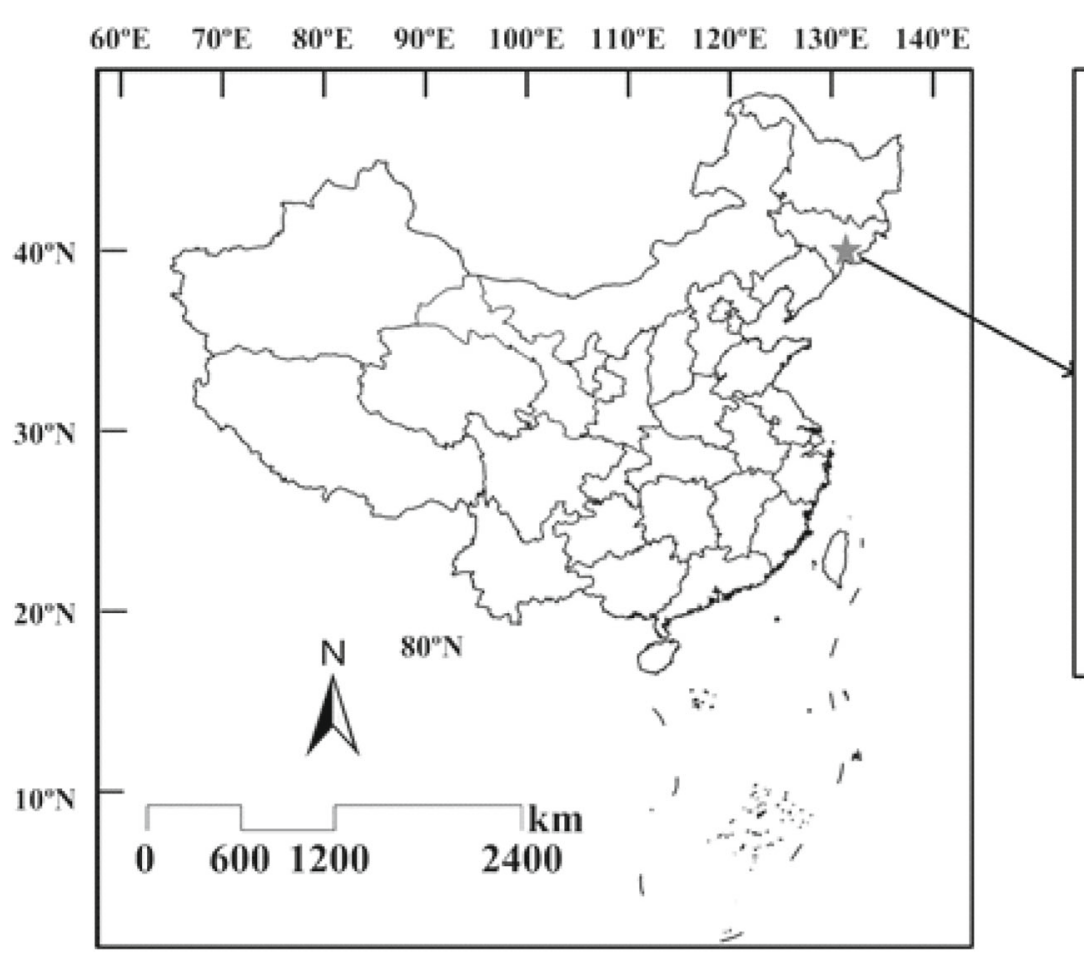

Fig. 1 Location of the plots

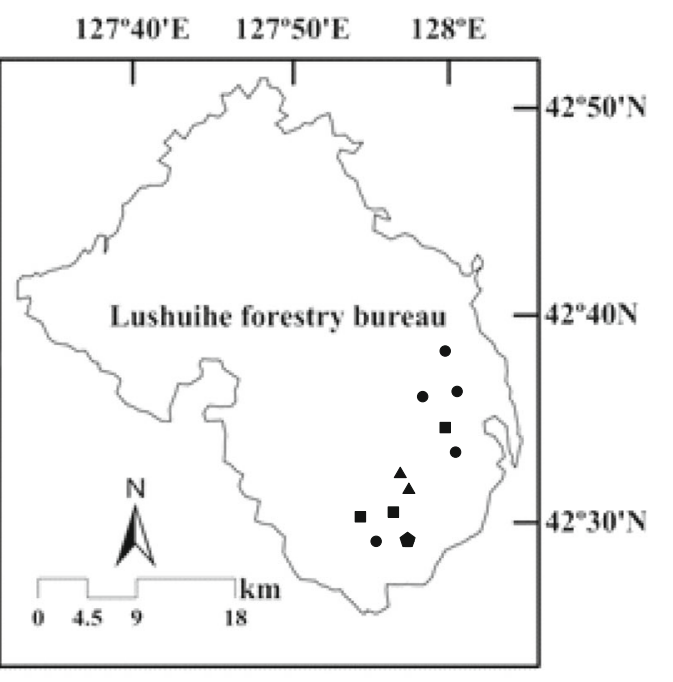

$\triangle$ CON, include: $A_{1}$ and $A_{2}$

- OBL, include: $B_{1}, B_{2}$, and $B_{3}$

- OKP, include: $\mathbf{C}_{\mathbf{1 - 5}}$

$B K B$, include: $D_{1}$ 
Table 1 Coordinates of the plots. CON Control plots, $O B L$ only broadleaved species logged, $O K P$ only Korean pine logged, $B K B$ both Korean pine and broadleaved species logged

\begin{tabular}{rrr}
\hline Plot & Latitude & Longitude \\
\hline $\mathrm{CON}$ & & \\
$\mathrm{A}_{1}$ & 42.48644 & 127.85742 \\
$\mathrm{~A}_{2}$ & 42.48551 & 127.86183 \\
$\mathrm{OBL}$ & & \\
$\mathrm{B}_{1}$ & 42.39425 & 127.81841 \\
$\mathrm{~B}_{2}$ & 42.39273 & 127.80989 \\
$\mathrm{~B}_{3}$ & 42.49993 & 127.96725 \\
$\mathrm{OKP}$ & & \\
$\mathrm{C}_{1}$ & 42.48596 & 127.97915 \\
$\mathrm{C}_{2}$ & 42.55942 & 127.98961 \\
$\mathrm{C}_{3}$ & 42.58141 & 127.94539 \\
$\mathrm{C}_{4}$ & 42.59014 & 127.97283 \\
$\mathrm{C}_{5}$ & 42.39095 & 127.87338 \\
$\mathrm{BKB}$ & & \\
$\mathrm{D}_{1}$ & 42.4189 & 127.87556 \\
\hline
\end{tabular}

temperature is $2.8^{\circ} \mathrm{C}$, and annual precipitation is approximately $1100 \mathrm{~mm}$. Typical natural vegetation of the study area is mixed broadleaved/Korean pine forest, dominated by Korean pine, Amur linden (Tilia amurensis Rupr.), Manchurian ash (Fraxinus mandshurica Rupr.), and Mongolian oak (Quercus mongolica Fisch. ex Ledeb.), which were regarded as commercially valuable tree species in the local logging system due to their high timber value. Secondary forests, which originated from primary forest but have since undergone various logging methods, are also very common in this area.

We selected four types of sites: one was a control site where no harvest had been conducted, and three sites that had been harvested selectively under three different species selection methods. One to five 1 -ha $(100 \times 100 \mathrm{~m})$ permanent plots, randomly located within each of the four site types were established (Table 2):

(1) CON plots $\left(A_{1}, A_{2}\right)$ : permanent plots in sites with no cutting;
(2) OBL plots $\left(\mathrm{B}_{1}, \mathrm{~B}_{2}\right.$, and $\left.\mathrm{B}_{3}\right)$ : permanent plots in sites where only commercial broadleaved trees were cut, which included Amur linden, Manchurian ash and Mongolian oak;

(3) OKP plots $\left(\mathrm{C}_{1}-\mathrm{C}_{5}\right)$ : permanent plots in sites where most cut trees were only Korean pine; and

(4) BKB plot $\left(D_{1}\right)$ : permanent plot in site where both Korean pine and broadleaved trees were cut.

We chose these plots based on forest resource inventory data from the 1980s. Elevation, stand condition and species composition of these plots were all similar before they were logged. All selectively harvested permanent plots were treated in 1980s; hence, their post-harvest forest stand dynamics had a similar time span.

\subsection{Data collection}

Data were collected from each permanent plot during the summers of 2010 and 2011. We divided each $100 \times 100 \mathrm{~m}$ main plot into $25,20 \times 20 \mathrm{~m}$ subplots. All live trees $>2 \mathrm{~cm} \mathrm{DBH}$ were then marked and mapped within each subplot. DBH of each tree was measured and recorded by species. The individual trees were located by measuring the horizontal distance to the left and bottom edge of the subplot. Five mixed soil samples (from $0 \mathrm{~cm}$ to $50 \mathrm{~cm}$ at $10-\mathrm{cm}$ intervals) were collected from the center of each subplot proceeding from the upperright corner to the lower left corner of each main plot. Total soil nitrogen (TN) content of each sample was measured in the laboratory using the Kjeldahl method (Bremner 1960).

\subsection{Data analysis}

\subsubsection{Stand structure and composition}

Based on tree diameter (DBH), all marked trees were classified into three groups: small (saplings, $>2$ and $\leq 8 \mathrm{~cm}$ ), medium $(>8$ and $\leq 20 \mathrm{~cm})$, and large (mature, $>20 \mathrm{~cm})$. The number of stems then was counted. Differences in tree density and TN

Table 2 Plots and stand information by logging treatment. The logged broadleaved tree species includes Manchurian ash, Mongolian oak, and Amur linden. Logging intensity was defined as proportion of the logged trees volume to the stand volume. $D B H$ Diameter at breast height

\begin{tabular}{|c|c|c|c|c|c|c|c|c|c|c|c|}
\hline \multirow[b]{3}{*}{ Plot name } & \multicolumn{11}{|c|}{ Treatment } \\
\hline & \multicolumn{2}{|l|}{$\mathrm{CON}$} & \multicolumn{3}{|l|}{ OBL } & \multicolumn{5}{|l|}{ OKP } & \multirow{2}{*}{$\frac{\mathrm{BKB}}{\mathrm{D}_{1}}$} \\
\hline & $\mathrm{A}_{1}$ & $\mathrm{~A}_{2}$ & $\mathrm{~B}_{1}$ & $\mathrm{~B}_{2}$ & $\mathrm{~B}_{3}$ & $\mathrm{C}_{1}$ & $\mathrm{C}_{2}$ & $\mathrm{C}_{3}$ & $\mathrm{C}_{4}$ & $\mathrm{C}_{5}$ & \\
\hline Canopy coverage (\%) & 95 & 90 & 80 & 85 & 80 & 85 & 80 & 80 & 85 & 85 & 80 \\
\hline Stem density $\left(\right.$ stems $\mathrm{ha}^{-1}$ ) & 1185 & 918 & 1009 & 781 & 996 & 1843 & 2038 & 1684 & 1766 & 1607 & 945 \\
\hline Mean tree $\mathrm{DBH}(\mathrm{cm})$ & 13.06 & 15.4 & 14.18 & 12.51 & 13.31 & 7.94 & 8.05 & 9.7 & 8.76 & 8.93 & 10.84 \\
\hline Logging intensity (\%) & - & - & 25 & 40 & 30 & 40 & 40 & 30 & 30 & 40 & 40 \\
\hline Time of logging (year) & - & - & 1985 & 1987 & 1985 & 1985 & 1980 & 1985 & 1980 & 1980 & 1989 \\
\hline
\end{tabular}


within and among treatments were tested using ANOVA. Correlation between density of saplings and TN content were tested. All statistical analyses were performed using SPSS 14.0 software.

\subsubsection{Spatial point pattern analysis}

We used Ripley's K-function to analyze the spatial distribution pattern of each tree species and the spatial association between trees in each permanent plot (Haase 1996). Ripley's $\mathrm{K}$-function has been used widely in plant ecology to characterize the spatial patterns of species. We used the Kest model, provided by the package "spatstat" (Baddeley and Turner 2005) in " $\mathrm{R} X 64$ 3.1.3" ( $\mathrm{R}$ Core Team 2015) to describe the aggregation, randomness, and regularity of tree species at any given lag distance. Then, we used the Kmulti model to describe spatial association within two types of trees (e.g., large vs. small trees) with an "isotropic" edge correction method (Baddeley and Turner 2005). The observed K-function was compared with $99 \%$ confidence interval envelopes based on 99 completely random simulations both in Kest model and Kmulti model. We also used a clustering index (CI) to measure the overall amount of spatial distribution pattern across various lag distances (Genton et al. 2006). The CI is defined as:

$\mathrm{CI}(r)=\int_{0}^{r}\left[\frac{K(r)-\pi r^{2}}{E(r)-\pi r^{2}}\right] \mathrm{d} r$

Where, $\mathrm{r}$ is a given lag distance. $\mathrm{K}(\mathrm{r})$ is $\mathrm{K}$ value that generated by Kest or Kmulti model at scale $\mathrm{r} . \pi r^{2}$ is the expected $\mathrm{K}$ function of a completely spatial random (CSR) process. $\mathrm{E}$ is the envelop curve of the 99 simulations of a CSR. CI $>1$ or $<-1$ indicates a significant clustering or regularity from the data, respectively. A larger positive CI indicates a higher degree of aggregation, while a smaller negative CI indicates a higher degree of regular distribution (Yang et al. 2007). CI can also be used to test whether there is a significant overall positive or negative spatial association between two types of trees when $K$ is calculated from the Kmulti model.

Principal component analysis (PCA) was used to discriminate the effects of logged tree species selection, logging intensity, and soil $\mathrm{N}$ concentration that impact the species spatial association. Spatial associations (including all associations among large trees, large trees and saplings, and among saplings of every identified tree species) that presented by Kvalue across the $0-25 \mathrm{~m}$ scale in each plot were used as the main matrix in the PCA. Logged species selection, logging intensity, tree density and soil $\mathrm{N}$ concentration of each plot was submitted to PCA as the second matrix (influence factors). The PCA was calculated using the software "PCORD 5" (Ellison 1998).

\section{Results}

\subsection{Stand structure}

Total stem density (stems $\mathrm{ha}^{-1}$ ) averaged $1,051 \pm 189$ at uncut control (CON) plots, $928 \pm 128$ at plots where only broadleaved tree species were logged (OBL), 1,788 \pm 166 at plots where only Korean pine was logged (OKP), and 945 at plots where both broadleaved tree species and Korean pine were logged (BKB, Table 2). Saplings made up a large proportion of total stem density in all treatments, accounting for $57.4 \%$ at CON plots to $74.0 \%$ at OKP plots (Fig. 2). Densities of Korean pine (KP) and commercial broadleaved tree species (CBL) saplings were significantly higher in the plots where only Korean pine was logged (KP: 130 stems ha ${ }^{-1}$, CBL:493 stems ha ${ }^{-1}$ ), or where both broadleaved tree species and Korean pine were logged (KP: 86 stems ha $^{-1}$, CBL: 375 stems $^{-1}$ ) than those in control plots (KP: 2 stems ha ${ }^{-1}, \mathrm{CBL}: 212$ stems $^{-1} \mathrm{a}^{-1}$ ) and plots where only broadleaved tree species were logged (KP: 1 stems ha ${ }^{-1}$, CBL:181 stems ha ${ }^{-1}$, Fig. 2).

\subsection{Soil nitrogen}

Total soil nitrogen (TN) content represented a gradient from $2.21 \pm 0.46 \mathrm{mg} \mathrm{g}^{-1}$ to $3.53 \pm 0.35 \mathrm{mg} \mathrm{g}^{-1}$ at the plot level (Fig. 3). However, we did not observe any significant differences in TN content among treatments $(P>0.05)$. Variation of TN content within plots was greater than that between treatments (Fig. 3). In addition, no statistically significant correlation occurred between TN and sapling density of each major tree species $(P>0.05)$.

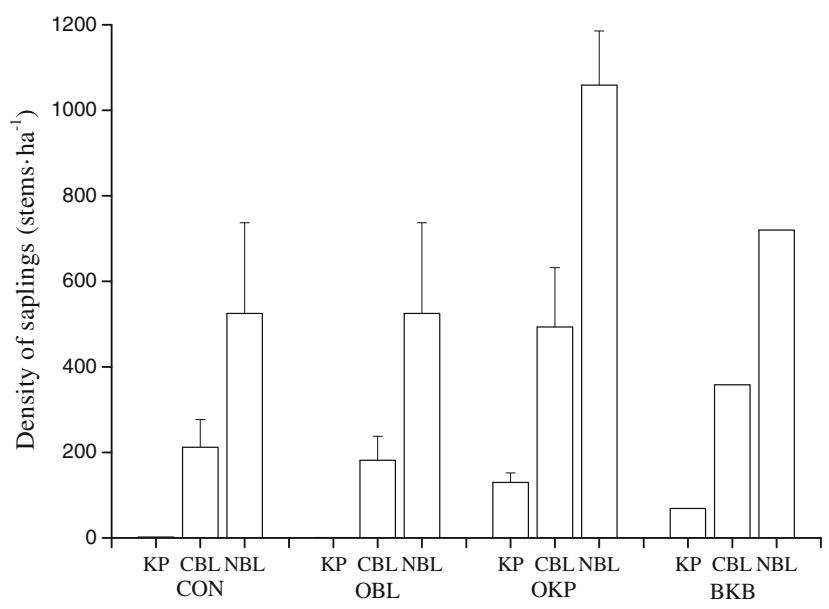

Fig. 2 Mean density of saplings by selective logging treatment and species group with standard deviations (error bars) 
Fig. 3 Soil total nitrogen (TN) content at each plot. Difference of $\mathrm{TN}$ within each plot $(n=5)$ and among treatments $[n=10$, plots where both broadleaved tree species and Korean pine were logged (BKB) were not included because there was no replicate] were tested by ANOVA. None were significant at $P<0.05$ level

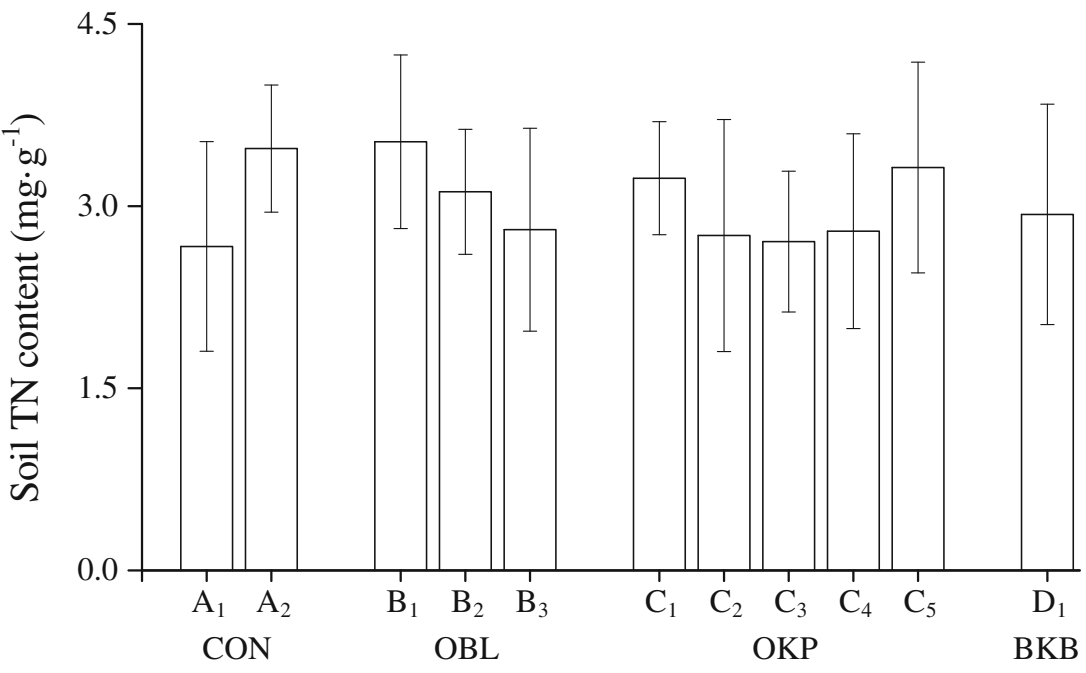

\subsection{Spatial distribution pattern of tree species}

The distribution pattern of major tree species varied among sites that were subject to different selective logging treatments and tree size class (Fig. 4). At the control (CON) plots, all saplings, medium-size and large trees of Korean pine and broadleaved species were distributed randomly at the scale of this analysis. Only Amur linden sapling at $\mathrm{A}_{2}$ exhibited an aggregated distribution pattern.

At the OBL plots where only broadleaved tree species were logged, the distribution of large-size Korean pine was random in all three plots, although it showed a weak trend toward a regular distribution at $\mathrm{B}_{1}$, and an aggregated trend at $\mathrm{B}_{2}$ and $\mathrm{B}_{3}$. Medium-size Korean pine was distributed randomly at $\mathrm{B}_{3}$.

\section{DBH groups (cm):}

KP. $\circ 2-8$

$\circ$ 8-20 $\bigcirc 20$ CBL: $\triangle$ 2-8 $\triangle$ 8-20 $\triangle>20$ NBL: $\times$

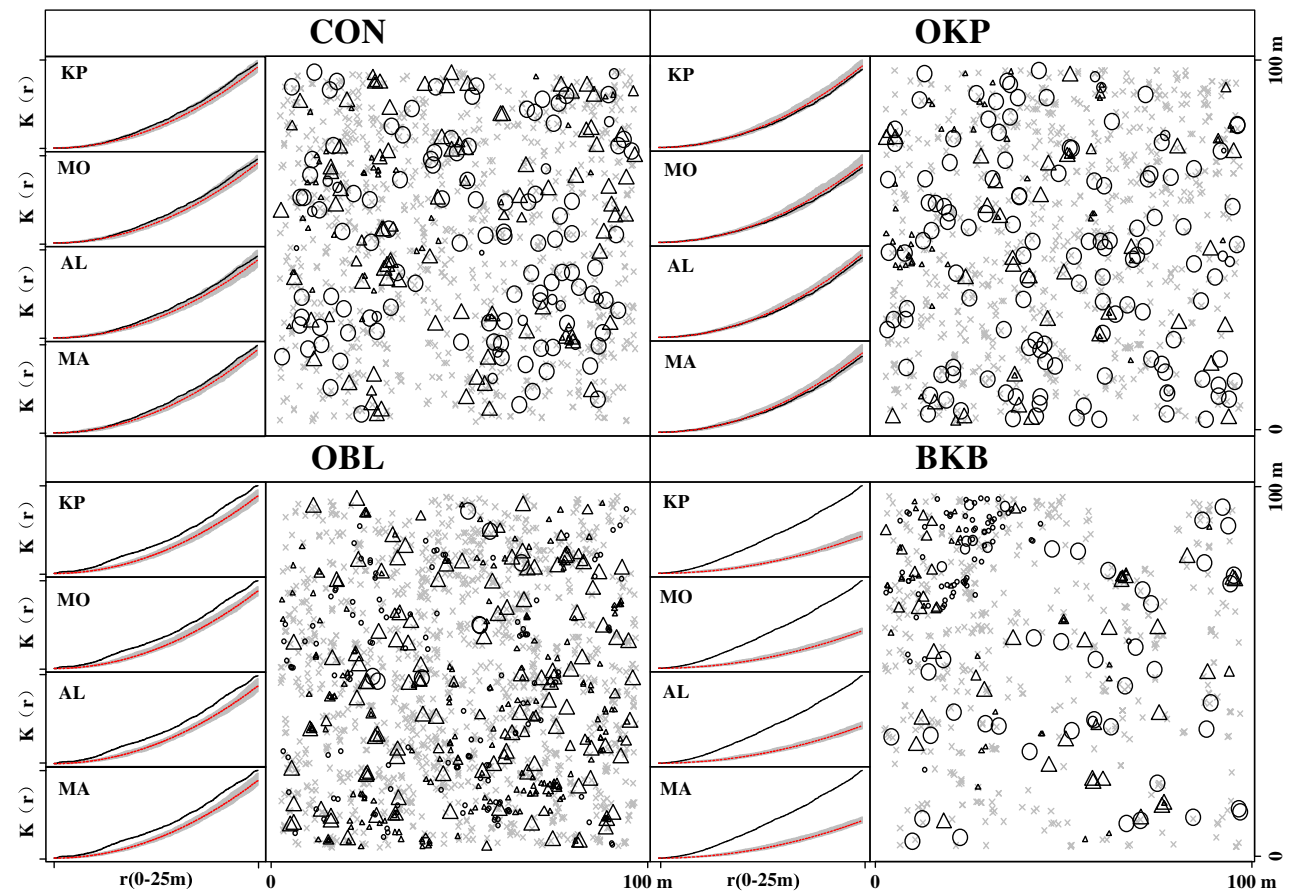

Fig. 4 Spatial distributions of all individual trees [diameter at breast height $(\mathrm{DBH})>2 \mathrm{~cm}$ ] in four representative 1-ha plots that correspond to four different logging treatments: $C O N$ control uncut treatment, $O K P$ only Korean pine logged, $O B L$ only broadleaved tree species logged, $B K B$ both Korean pine and broadleaved tree species logged. The vertical axis of each graph shows Ripley's K-function value. Red lines
Theoretical $K(r)$ values of a completely spatial random (CSR) process, black lines observed values. The shaded area in each graph represents the $99 \%$ confidence envelope based on 99 simulations. A black line above the envelope suggests an aggregated distribution; a black line within the envelope suggests a random distribution; and a black line below the envelope suggests a regular distribution 
Saplings of Korean pine were too few to form a spatial distribution test. Large-size Amur linden was distributed randomly at $B_{1}$ and $B_{2}$, and found aggregated at $B_{3}$. Saplings of Amur linden at $B_{1}$ and $B_{2}$ were aggregated. Large Mongolian oak was distributed randomly at $\mathrm{B}_{1}$ and $\mathrm{B}_{3}$, and aggregated at $\mathrm{B}_{2}$. Large Manchurian ash was distributed randomly at $\mathrm{B}_{1}$ and $\mathrm{B}_{3}$.

At the OKP plots where only Korean pine was logged, most large-size Korean pine, Amur linden, Mongolian oak, and Manchurian ash were distributed randomly, except for Mongolian oak at $\mathrm{C}_{4}$, whose distribution pattern was aggregated. Medium-size Korean pine was aggregated at $\mathrm{C}_{5}$, while three other medium-sized broadleaved tree species were distributed randomly at OKP plots. The saplings of almost all species exhibited an aggregated distribution.

At the BKB plot where both Korean pine and broadleaved tree species were logged, all large-size trees of each major tree species were distributed randomly. The distributions of Korean pine saplings and Mongolian oak saplings were aggregated, whereas saplings of other species were distributed randomly (Table 3).

\subsection{Spatial associations between tree species}

\subsubsection{Spatial association between large-size broadleaved tree species and Korean pine sapling}

Strong inter-specific competition was evident between large Amur linden and Korean pine sapling at 7 of 11 plots (2 plots were significant, Fig. 5). Significant positive association between large Mongolian oak and Korean pine sapling occurred at three plots $\left(\mathrm{C}_{2}, \mathrm{C}_{4}\right.$ and $\left.\mathrm{C}_{5}\right)$, while significantly negative associations between large Mongolian oak and Korean pine sapling occurred at one plot $\left(\mathrm{B}_{2}\right)$. Associations between Manchurian ash and Korean pine sapling were positive at four of nine logged plots $\left(\mathrm{B}_{1}, \mathrm{~B}_{3}, \mathrm{C}_{2}\right.$ and $\left.\mathrm{C}_{5}\right)$, although it was significant at only one plot $\left(\mathrm{C}_{5}\right)$. However, significant negative associations between large Manchurian ash and Korean pine sapling were found at $C_{3}$ and $D_{1}$.

\subsubsection{Spatial associations between large-size Korean pine and saplings of commercial broadleaved species}

Amur linden was positively correlated with large Korean pines at 9 of 11 plots (4 plots were significant). In contrast, Mongolian oak at 4 of 11 plots ( 2 plots were significant) and Manchurian ash at all 11 plots (6 plots were significant) were spatially regularly distributed when growing among large Korean pine (Fig. 6).

\subsubsection{Spatial associations between large Korean pine and large $C B L$}

Inter-specific competition between large trees of Korean pine and Mongolian oak at $\mathrm{C}_{2}$ was suggested by their negative associations based on SPP analysis. At $\mathrm{D}_{1}$, Amur linden aggregated strongly around Korean pine. At the other plots,

Table 3 Clustering index (CI) by species and diameter (DBH) class for the four classes of logging treatment by plots

\begin{tabular}{|c|c|c|c|c|c|c|c|c|c|c|c|c|}
\hline & \multicolumn{3}{|c|}{ Korean pine } & \multicolumn{3}{|c|}{ Amur linden } & \multicolumn{3}{|c|}{ Mongolian oak } & \multicolumn{3}{|c|}{ Manchurian ash } \\
\hline & $\mathrm{S}^{\mathrm{a}}$ & M & $\mathrm{L}$ & $\mathrm{S}$ & M & $\mathrm{L}$ & $\mathrm{S}$ & M & $\mathrm{L}$ & $\mathrm{S}$ & M & $\mathrm{L}$ \\
\hline \multicolumn{13}{|c|}{$\mathrm{CON}$} \\
\hline $\mathrm{A}_{1}$ & $\mathrm{NA}^{\mathrm{b}}$ & 0.46 & 0.38 & NA & NA & 0.56 & NA & NA & 0.94 & 0.41 & -0.04 & -0.22 \\
\hline $\mathrm{A}_{2}$ & NA & 0.02 & 0.48 & $2.33^{*}$ & -0.04 & -0.36 & NA & NA & 0.31 & NA & NA & 0.25 \\
\hline \multicolumn{13}{|c|}{ OBL } \\
\hline $\mathrm{B}_{1}$ & NA & NA & -0.16 & $2.53^{*}$ & NA & -0.12 & NA & NA & 0.2 & NA & NA & 0.10 \\
\hline $\mathrm{B}_{2}$ & NA & NA & 0.21 & $1.68^{*}$ & NA & 0.07 & NA & NA & $1.08^{*}$ & NA & NA & NA \\
\hline $\mathrm{B}_{3}$ & NA & 0.19 & 0.49 & NA & NA & 1.02 & NA & NA & -0.10 & NA & NA & 0.92 \\
\hline \multicolumn{13}{|c|}{ OKP } \\
\hline $\mathrm{C}_{1}$ & $2.16^{*}$ & NA & 0.41 & 0.88 & -0.12 & -0.19 & NA & NA & 0.04 & $4.78^{*}$ & 0.54 & NA \\
\hline $\mathrm{C}_{2}$ & $2.86^{*}$ & NA & NA & $4.99 *$ & -0.14 & -0.02 & 2.24 & 0.54 & 0.72 & $5.47^{*}$ & 0.99 & 0.03 \\
\hline $\mathrm{C}_{3}$ & $8.89 *$ & NA & 0.73 & $1.23^{*}$ & 0.2 & 0.36 & NA & NA & 0.49 & $3.06^{*}$ & NA & 0.56 \\
\hline $\mathrm{C}_{4}$ & $2.66^{*}$ & NA & NA & $1.01 *$ & 0.14 & 0.40 & NA & NA & $2.08^{*}$ & $6.33^{*}$ & NA & 0.54 \\
\hline $\mathrm{C}_{5}$ & $4.33^{*}$ & 1.15 & -0.07 & $5.83^{*}$ & -0.22 & 0.00 & 0.67 & 0.49 & 0.02 & 0.33 & NA & 0.52 \\
\hline \multicolumn{13}{|c|}{$\mathrm{BKB}$} \\
\hline $\mathrm{D}_{1}$ & $19.96^{*}$ & $1.14 *$ & 0.01 & 0.15 & 0.36 & 0.36 & $3.11 *$ & $2.82 *$ & NA & NA & NA & 0.25 \\
\hline
\end{tabular}

${ }^{*} \mathrm{CI}$ value is significant based on the envelope analysis ( $>1$ indicates overall spatial distribution pattern is aggregated; and $<-1$ indicates regularity)

${ }^{\text {a }}$ Small (S): 2-8 cm, Medium (M) : $>8-20 \mathrm{~cm}$, Large (L) : $>20 \mathrm{~cm}$

${ }^{\mathrm{b}}$ Size of observation is not large enough to run analysis 


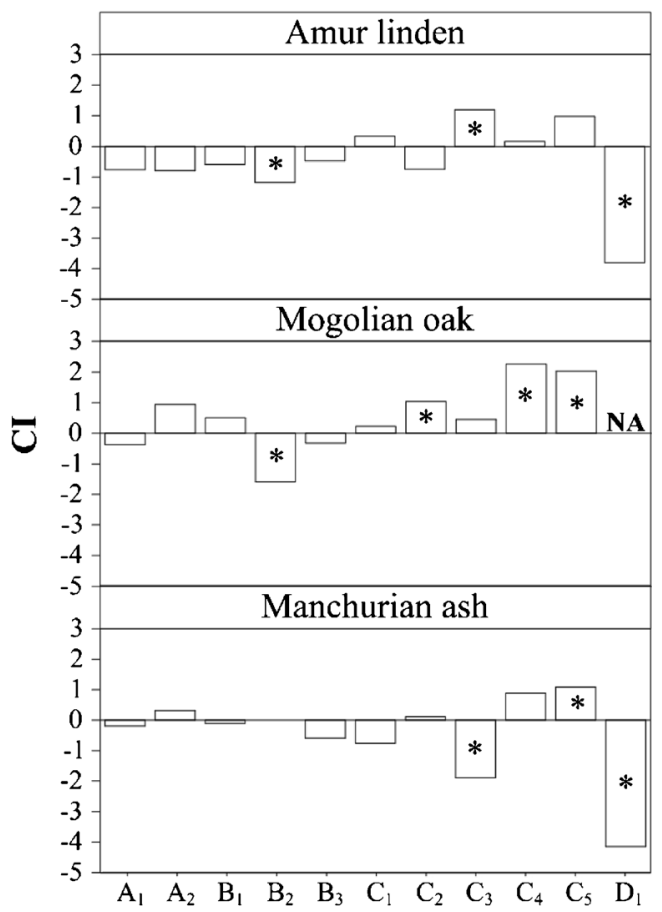

Fig. 5 Clustering index (CI) between Korean pine saplings and large broadleaved trees. CI value is the ratio of area between $\mathrm{K}(\mathrm{r})$ curve and theoretical curve to area between envelope curve near $\mathrm{K}(\mathrm{r})$ and theoretical curve. Saplings: $2<\mathrm{DBH} \leq 8 \mathrm{~cm}$, large trees: $\mathrm{DBH}>20 \mathrm{~cm}$

inter-specific competition between large Korean pine and CBL was not detected; most of those trees were represented by a random spatial association.

\subsubsection{Intra-specific spatial associations}

There was evidence of intra-specific competition between large trees and saplings of Korean pine at 10 plots (10 plots were all significant); Amur linden at 6 of 11 plots ( 2 plots were significant), and Manchurian ash at 9 of 11 plots (4 plots were significant; Fig. 7).

\subsection{Effect of logged species selection on species spatial association}

The PCA of the species spatial distribution patterns and spatial associations (including all associations among large trees, large trees and saplings, and among saplings of every tree species) at each plot clearly discriminated these plots into two groups: (1): the group in which Korean pine was not logged, including all CON and OBL plots; and (2) the group in which Korea pine was logged, including all OKP and BKB plots (Fig. 8). Axis 1 (density of large Korean pine) and 3 (density of large broadleaved trees) of the ordination explained $77 \%$ and $18 \%$ of the variation in the distance matrix, respectively.

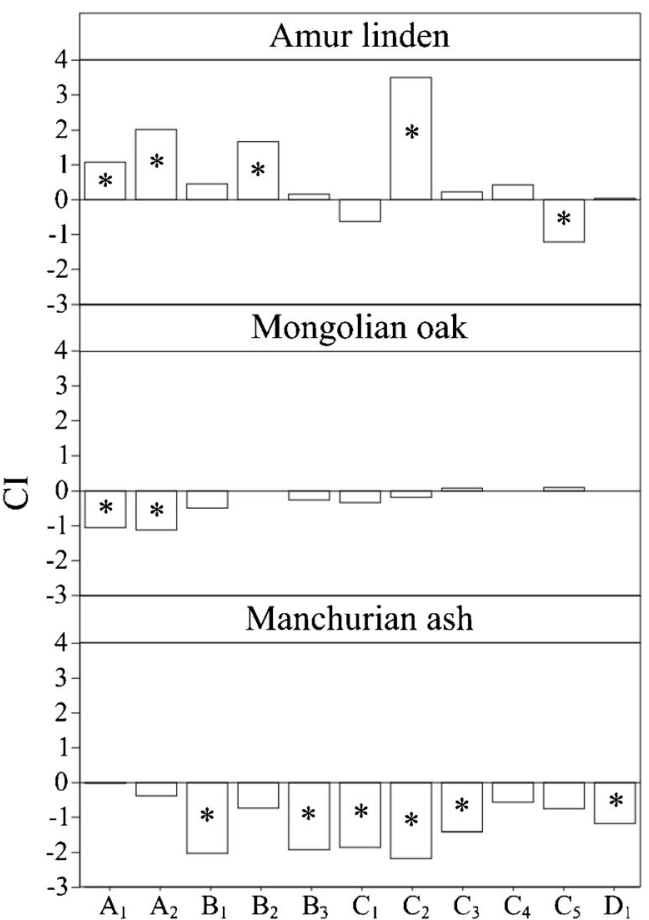

Fig. 6 Clustering index (CI) between large Korean pines and broadleaved tree saplings. CI value is the ratio of area between $\mathrm{K}(\mathrm{r})$ curve and theoretical curve to area between envelope curve near $\mathrm{K}(\mathrm{r})$ and theoretical curve. Saplings: $2<\mathrm{DBH} \leq 8 \mathrm{~cm}$, large trees: $\mathrm{DBH}$ $>20 \mathrm{~cm}$

\section{Discussion}

\subsection{Effect of selective logging on species spatial distribution pattern}

In our study, different selective logging treatments showed a profound impact on the spatial distribution patterns of major tree species in mixed broadleaved/Korean pine forest. Removal of broadleaved tree species did not significantly change the distribution pattern of major tree species, while removal of Korean pine shifted the distribution pattern of these tree species from random to aggregation. That is because most tree species in our study were aggregately distributed in their young age at the scale of this analysis, logging of Korean pine significantly increased the proportion of saplings of all major tree species, and a high proportion of saplings resulted in the aggregated distribution pattern of these tree species. Our finding of aggregated regeneration patterns was similar to results reported in managed stands in Virginia and Western Montana, in the United States (Call and Nilsen 2003; Fajardo et al. 2006). This aggregation of regeneration in managed stands is likely driven by many of the same factors as found under natural stand dynamics. Various processes can lead to an aggregated distribution pattern of recruitment, e.g., seed characteristics and dispersal mechanism, or increased resource availability within canopy gaps (Nathan 
Fig. 7 Clustering index (CI) between large trees and conspecific saplings. CI value is the ratio of area between $\mathrm{K}(\mathrm{r})$ curve and theoretical curve to area between envelope curve near K(r) and theoretical curve. Saplings: $2<\mathrm{DBH} \leq 8 \mathrm{~cm}$, large trees: DBH $>20 \mathrm{~cm}$

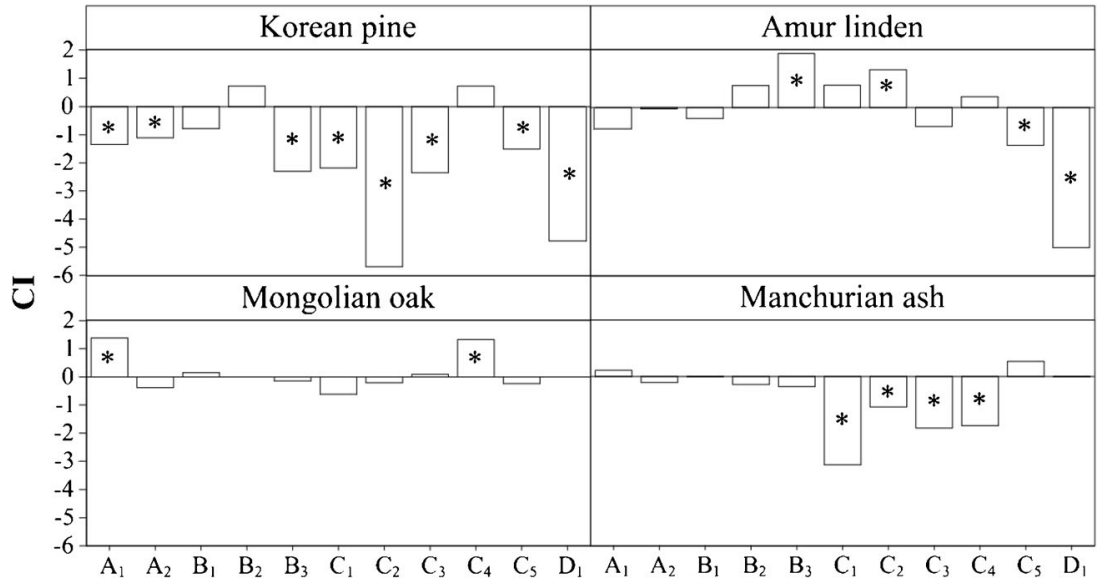

and Muller-Landau 2000). In our case, the aggregation of saplings was more likely related to seed characteristics and dispersal mechanism. For example, each cone of Korean pine contains hundreds of seeds. Thus, cone location largely predetermines the future distribution of pine seeds and seedlings.

\subsection{Effect of interactions between tree species on regeneration pattern in post harvested forests}

A broad range of studies in tropical and temperate forests has demonstrated that variations in tree species composition caused by species-based selective logging had resulted in significant differences in post-harvested regeneration pattern (Cain 1991; Clark and Covey 2012; Corria-Ainslie et al. 2015). Both positive and negative plant-plant interactions

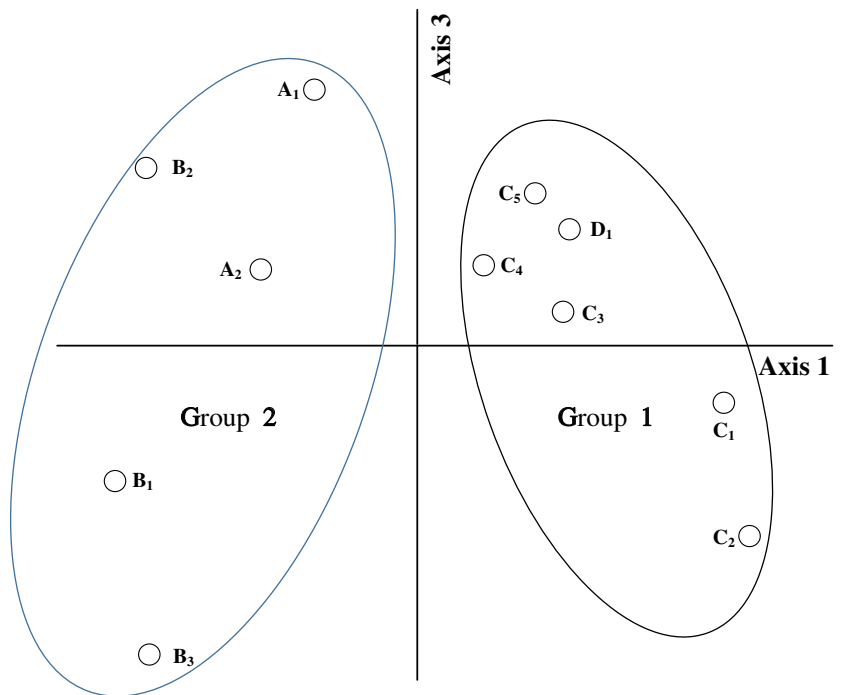

Fig. 8 Principal component analysis (PCA) of spatial associations among trees of each plot. Plot information including its code is provided in Table 1. Spatial associations (including all associations among large trees, large trees and saplings, and among saplings of every identified tree species) presented by K-value across 0-25 m scale in each plot was used as the main matrix in PCA; and logged species selection, logging intensity and soil $\mathrm{N}$ concentration of each plots was submitted to PCA as second matrix (influencing factors) between remaining trees and regeneration patterns have been observed in post-harvested stands (Fajardo et al. 2006; Clark and Covey 2012). Our results were consistent with these previous studies, strong competition between mature Korean pine and saplings of both broadleaved tree species and Korean pine, indicated by the significant negative spatial association that was observed in most of our plots. Several mechanisms may provide explanations for this negative spatial association. Light availability was profoundly affected by logging and makes an important contribution to the dynamics of species composition during succession (Gray and Spies 1996). Mature Korean pines were, on average, taller than mature broadleaved trees (Tao et al. 2011). Thus, they can effectively capture more light at the $\mathrm{CON}, \mathrm{OBL}$ and BKB plots, where the density and basal area of mature Korean pine was greater than that of other species. Although seedlings of Korean pine are considered shade tolerant, this species' light requirement increases with tree age (Sun et al. 2009). Logging of mature Korean pines thus can increase light not only for saplings broadleaved species, but also for Korean pine saplings. Therefore, logging of Korean pine can increase the density of saplings of almost all major tree species. Another possible explanation for the negative spatial association between mature trees and saplings may be allelopathy. Previous studies in our study area have shown that the survival rate of seedlings of broadleaved tree species such as Manchurian ash decreased sharply after the addition of litter powder or leaf extracts of Korean Pine (Xu et al. 1992; Bai and Zhang 2013). Regeneration failure caused by allelopathy was also observed in various temperate forests (Fernandez et al. 2008; Robakowski and Bielinis 2011; Singh and Rattan 2013).

\subsection{Factors influencing forest species coexistence}

Previous research has found that both biotic factors, such as competition, and abiotic factors (e.g., soil nutrient status) can profoundly impact species coexistence and the structure dynamics of natural forests (Palmiotto et al. 2004; Getzin et al. 
2006). Forest management practices with various logging methods and intensities can have different effects via changing these two major driving factors (Canham et al. 2006; Villela et al. 2006). Because the primary objective of this study was to examine the effect of tree species selection of selective logging systems on forest structure dynamics, and its underlying mechanisms, logging intensity was fixed in a common range with relatively low variation (Table 2 ). In our research, a strong effect of biotic factors such as competition was evident by the negative spatial association between large trees and saplings, especially con-specific large trees and saplings. In contrast, we found no significant effects of soil nutrient status on density and spatial distribution pattern of major tree species in our plots. Similar results have been reported from other temperate forests in central Japan and the north of Spain, where the regeneration pattern was driven mainly by biotic factors (Uria-Diez et al. 2013; Masaki et al. 2015). These results collectively suggest that competition, especially intra-specific competition, may be the major force underlying the spatial structure of trees in these temperate forests following selective logging.

Although our results did not find a significant effect of soil nitrogen, this does not mean that abiotic factors are not important in regulating post-harvest forest dynamics. Furthermore, our results may have been partially related to the low heterogeneity of environmental resources within and between plots (Fig. 3). At all of our study plots, local-scale topography was relatively homogeneous both within and among plots. Therefore, soil resources showed low spatial heterogeneity. Moreover, our study was constrained to the spatial scale of plots wherein we measured soil resources as plot averages. Therefore, our results may not accurately reflect actual soil heterogeneity across a given plot. Also, our study considered only total soil nitrogen, which overlooked other potentially growth-limiting soil nutrient variables such as available nitrogen and phosphorus.

\subsection{Implications for managing uneven-aged temperate forests}

The main results of this study have interesting management implications for the establishment and release of regeneration in temperate forest managed under the individual tree selection system. They indicate that interactions among tree species are an important driving factor influencing forest regeneration pattern and dynamics. To maintain diversity and vigorous growth in post-harvested stands, interaction among logged trees, remaining trees, and regenerations should be considered when implementing a selective logging scheme in temperate forests.

Our study provided a stark example of this point, as mixed broadleaved/Korean pine forest was buffered from logging impacts through reduced removal intensity, and logging of
Korean pine was prohibited. This has long been considered necessary for balancing timber production with forest sustainability. Although large Korean pines have been well protected, such protection has itself resulted in poor regeneration of both Korean pine and major broadleaved species. In turn, this can be expected to eventually lead to a loss in species diversity in this forest. Even with artificial regeneration, and regardless of which species are planted, the presence of large-size Korean pines at high densities will likely inhibit the regeneration of most major tree species. Therefore, for the purpose of promoting natural forest regeneration with high diversity in this type of temperate forest, we propose appropriately controlling the dominant species to reduce its negative effects on regeneration.

\section{Conclusion}

In temperate forests, selective logging can exert varied effects on forest regeneration pattern in post-harvested stands, mainly through the change of species interactions such as competition by altering post-harvest forest composition and tree locations. Our study showed that logging the foundational species of late-successional conifer trees (i.e., Korean pine) in this mixed forest can result in abundant regeneration of both the conifer species and many other broadleaved tree species. In contrast, tree regeneration is very limited in forest where only broadleaved tree species were harvested, due to the strong competition-exclusion effect of the competition-superior conifer species. This indicates that, if we ignore spatial interactions, we risk being unable to effectively protect an endangered tree species, or to accurately predict the dynamics of even a very simple ecological system, regardless of how accurately we measure the underlying demographic rates. Thus, to maintain healthy forest dynamics, forest managers should consider species interactions and controlling the density of competitionsuperior species when implementing selective logging systems. More specifically, to ensure continuous regeneration of the protected Korean pine and commercial broadleaved tree species, local forest managers should also consider the removal of large-size Korean pine trees and altering the distribution of remained large Korean pines to reduce the negative effect of those competition-superior trees on regeneration.

Acknowledgments We wish to thank Dr. Paul Johnson for his careful editing and valuable suggestions, and Dr. Peter J. Weisberg for his invaluable comments in earlier versions of the manuscript. The two anonymous reviewers and the editor provided constructive comments that helped improve this manuscript.

Funding Financial support was provided by National Key Technologies R \& D Program of China (2012BAD22B04), National Natural Science Foundation of China (No. 41222004, No. 31300526), and CFERN \& GENE Award Funds on Ecological Paper. 


\section{References}

Baddeley A, Turner R (2005) spatstat: an R package for analyzing spatial point patterns. J Stat Softw 12:1-42

Bai G, Zhang Y (2013) Natural regeneration and its influencing factors of manchurian ash (in Chinese). J Northeast Forest Univ 41:7-13

Bischoff W, Newbery DM, Lingenfelder M, Schnaeckel R, Petol GH, Madani L, Ridsdale CE (2005) Secondary succession and dipterocarp recruitment in Bornean rain forest after logging. For Ecol Manage 218:174-192. doi:10.1016/j.foreco.2005.07.009

Bréda N, Granier A, Aussenac G (1995) Effects of thinning on soil and tree water relations, transpiration and growth in an oak forest (Quercus petraea (Matt.) Liebl.). Tree Physiol 15:295-306

Bremner J (1960) Determination of nitrogen in soil by the Kjeldahl method. J Agric Sci 55:11-33. doi:10.1017/S0021859600021572

Cain MD (1991) Hardwoods on pine sites: competition or antagonistic symbiosis. For Ecol Manage 44:147-160

Call LJ, Nilsen ET (2003) Analysis of spatial patterns and spatial association between the invasive tree-of-heaven (Ailanthus altissima) and the native black locust (Robinia pseudoacacia). Am Midl Nat 150: $1-14$

Canham CD, Papaik MJ, Uriarte M, McWilliams WH, Jenkins JC, Twery MJ (2006) Neighborhood analyses of canopy tree competition along environmental gradients in New England forests. Ecol Appl 16:540 554

Castro-Luna AA, Castillo-Campos G, Sosa VJ (2011) Effects of selective logging and shifting cultivation on the structure and diversity of a tropical evergreen forest in south-eastern Mexico. J Trop For Sci 23: $17-34$

Clark JA, Covey KR (2012) Tree species richness and the logging of natural forests: a meta-analysis. For Ecol Manage 276:146-153. doi:10.1016/j.foreco.2012.04.001

Corria-Ainslie R, Camarero JJ, Toledo M (2015) Environmental heterogeneity and dispersal processes influence post-logging seedling establishment in a Chiquitano dry tropical forest. For Ecol Manage 349:122-133. doi:10.1016/j.foreco.2015.03.033

Dai L, Chen G, Deng H, Ji L, Hao Z, Wang Q (2004) Structure characteristics and health distance assessment of various disturbed communities of Korean pine and broadleaved mixed forest in Changbai Mountains (in Chinese). Chinese J Appl Ecol 15:1750-1754. doi: 10.13287/j.1001-9332.2004.0363

Dai L, Zhao F, Shao G, Zhou L, Tang L (2009) China's classificationbased forest management: procedures, problems, and prospects. Environ Manage 43:1162-1173

Dai L, Qi L, Wang Q, Su D, Yu D, Wang Y, Ye Y, Jiang S, Zhao W (2011a) Changes in forest structure and composition on Changbai Mountain in Northeast China. Ann Forest Sci 68:889-897. doi:10. 1007/s13595-011-0095-X

Dai L, Wang Y, Su D, Zhou L, Yu D, Lewis BJ, Qi L (2011b) Major forest types and the evolution of sustainable forestry in China. Environ Manage 48:1066-1078. doi:10.1007/s00267-011-9706-4

Dai L, Zhao W, Shao G, Lewis BJ, Yu D, Zhou L, Zhou W (2013) The progress and challenges in sustainable forestry development in China. Int J Sust Dev World 20:394-403. doi:10.1080/13504509. 2013.775193

Ellison AM (1998) PC-ORD: multivariate analysis of ecological data. Bull Ecol Soc Am 79:144-145

Fajardo A, Goodburn JM, Graham J (2006) Spatial patterns of regeneration in managed uneven-aged ponderosa pine Douglas-fir forests of Western Montana, USA. For Ecol Manag 223:255-266. doi:10. 1016/j.foreco.2005.11.022

Fernandez C, Voiriot S, Mevy JP, Vila B, Ormeno E, Dupouyet S, Bousquet-Melou A (2008) Regeneration failure of Pinus halepensis Mill.: the role of autotoxicity and some abiotic environmental parameters. For Ecol Manage 255:2928-2936. doi:10.1016/j. foreco.2008.01.072

Genton MG, Butry DT, Gumpertz ML, Prestemon JP (2006) Spatiotemporal analysis of wildfire ignitions in the St Johns River Water Management District, Florida. Int J Wildland Fire 15:87-97. doi:10. 1071/Wf04034

Getzin S, Dean C, He F, Trofymow JA, Wiegand K, Wiegand T (2006) Spatial patterns and competition of tree species in a Douglas-fir chronosequence on Vancouver Island. Ecography 29:671-682. doi:10.1111/j.2006.0906-7590.04675.x

Getzin S, Wiegand T, Wiegand K, He F (2008) Heterogeneity influences spatial patterns and demographics in forest stands. J Ecol 96:807820

Gray AN, Spies TA (1996) Gap size, within-gap position and canopy structure effects on conifer seedling establishment. J Ecol 84:635645. doi: $10.2307 / 2261327$

Haase P (1996) Spatial pattern analysis in ecology based on Ripley's Kfunction: introduction and methods of edge correction. J Veg Sci 7: 304-304

Harms KE, Condit R, Hubbell SP, Foster RB (2001) Habitat associations of trees and shrubs in a 50-ha neotropical forest plot. J Ecol 89:947959. doi:10.1046/j.0022-0477.2001.00615.x

Ishii HT, Tanabe S, Hiura T (2004) Exploring the relationships among canopy structure, stand productivity, and biodiversity of temperature forest ecosystems. For Sci 50:342-355

Linares JC (2013) Shifting limiting factors for population dynamics and conservation status of the endangered English yew (Taxus baccata L., Taxaceae). For Ecol Manage 291:119-127. doi:10.1016/j.foreco. 2012.11.009

Martinez I, Wiegand T, Gonzalez-Taboada F, Obeso JR (2010) Spatial associations among tree species in a temperate forest community in North-western Spain. For Ecol Manage 260:456-465. doi:10.1016/ j.foreco.2010.04.039

Masaki T, Hata S, Ide Y (2015) Heterogeneity in soil water and light environments and dispersal limitation: what facilitates tree species coexistence in a temperate forest? Plant Biol 17:449-458

Moore JR, Lyon AJ, Lehneke S (2012) Effects of rotation length on the grade recovery and wood properties of Sitka spruce structural timber grown in Great Britain. Ann For Sci 69:353-362. doi:10.1007/ s13595-011-0168-x

Nagaike T, Hayashi A (2004) Effects of extending rotation period on plant species diversity in Larix kaempferi plantations in central Japan. Ann For Sci 61:197-202. doi:10.1051/forest:204012

Nathan R, Muller-Landau HC (2000) Spatial patterns of seed dispersal, their determinants and consequences for recruitment. Trends Ecol Evol 15:278-285. doi:10.1016/S0169-5347(00)01874-7

Noble IR, Dirzo R (1997) Forests as human-dominated ecosystems. Science 277:522-525

Odion DC, Sarr DA (2007) Managing disturbance regimes to maintain biological diversity in forested ecosystems of the Pacific Northwest. For Ecol Manage 246:57-65. doi:10.1016/j.foreco.2007.03.050

Palmiotto PA, Davies SJ, Vogt KA, Ashton MS, Vogt DJ, Ashton PS (2004) Soil-related habitat specialization in dipterocarp rain forest tree species in Borneo. J Ecol 92:609-623

Pope I, Bowen D, Harbor J, Shao G, Zanotti L, Burniske G (2015) Deforestation of montane cloud forest in the Central Highlands of Guatemala: contributing factors and implications for sustainability in Q'eqchi' communities. Int J Sust Dev World 22:201212

R Core Team (2015) R: A language and environment for statistical computing. R Foundation for Statistical Computing, Vienna, Austria. URL http://www.R-project.org/

Robakowski P, Bielinis E (2011) Competition between sessile oak (Quercus Petraea) and black cherry (Padus Serotina): dynamics of seedlings growth. Pol J Ecol 59:297-306 
Shao G, Wang H, Dai L, Wu G, Li Y, Lang R, Song B (2005) Integrating stand and landscape decisions for multi-purposes of forest harvesting. For Ecol Manage 207:233-243

Singh O, Rattan V (2013) Allelopathic effects of Viburnum nervosum on seed germination and seedling growth of Abies pindrow Spach. Allelopathy J 32:113-122

Sist P, Picard N, Gourlet-Fleury S (2003) Sustainable cutting cycle and yields in a lowland mixed dipterocarp forest of Borneo. Ann For Sci 60:803-814. doi:10.1051/forest:2003075

Soalleiro RR, Murias MB, Gonzalez JGA (2007) Evaluation through a simulation model of nutrient exports in fastgrowing southern European pine stands in relation to thinning intensity and harvesting operations. Ann For Sci 64:375-384. doi:10.1051/forest:2007014

Sun Y, Zhu J, Yu L (2009) Photosynthetic charateristics of Pinus Koraiensis seedings under different light regimes (in Chinese). Chinese J Appl Ecol 28:850-857

Tao Y, Yin X, Tian Y, Xin W (2011) Study on intraspecific and interspecific competition of pinus Koraiensis broadleaf mixed forest in Changbai Mountain (in Chinese). J Beijing Norm Univ (Nat Sci) 47:428-431

Uria-Diez J, Ibanez R, Mateu J (2013) Importance of habitat heterogeneity and biotic processes in the spatial distribution of a riparian herb (Carex remota L.): a point process approach. Stoch Environ Res Risk A 27:59-76. doi:10.1007/s00477012-0569-x
Verschuyl J, Riffell S, Miller D, Wigley TB (2011) Biodiversity response to intensive biomass production from forest thinning in North American forests - a meta-analysis. For Ecol Manage 261:221-232

Villela DM, Nascimento MT, LEOCd Aragão, DMd Gama (2006) Effect of selective logging on forest structure and nutrient cycling in a seasonally dry Brazilian Atlantic forest. J Biogeogr 33:506-516

Wang X, Wiegand T, Wolf A, Howe R, Davies SJ, Hao Z (2011) Spatial patterns of tree species richness in two temperate forests. J Ecol 99: 1382-1393

Wu L, Liu J, Takashima A, Ishigaki K, Watanabe S (2013) Effect of selective logging on stand structure and tree species diversity in a subtropical evergreen broad-leaved forest. Ann For Sci 70:535-543. doi:10.1007/s13595-013-0292-x

Xu Z, Dai H, Li X (1992) A study on the influence of mainly associated tree species on the growth of pinus koraiensis (in Chiese). Sci Silva Sin 28:357-361

Yang J, He H, Shifley SR, Gustafson EJ (2007) Spatial patterns of modern period human-caused fire occurrence in the Missouri Ozark Highlands. For Sci 53:1-15

Yu D, Zhou L, Zhou W, Ding H, Wang Q, Wang Y, Wu X, Dai L (2011) Forest management in Northeast China: history, problems, and challenges. Environ Manage 48:1122-1135. doi:10.1007/s00267-0119633-4

Zhao F, Yang J, Liu Z, Dai L, He H (2011) Balancing multiple objectives using a classification-based forest management system in Changbai Mountains, China. Environ Manage 48:1136-1147 